\title{
External eating, impulsivity and attentional bias to food cues
}

Citation for published version (APA):

Hou, R., Mogg, K., Bradley, B. P., Moss-Morris, R., Peveler, R., \& Roefs, A. J. (2011). External eating, impulsivity and attentional bias to food cues. Appetite, 56(2), 424-427.

https://doi.org/10.1016/j.appet.2011.01.019

Document status and date:

Published: 01/04/2011

DOI:

10.1016/j.appet.2011.01.019

Document Version:

Publisher's PDF, also known as Version of record

Document license:

Taverne

Please check the document version of this publication:

- A submitted manuscript is the version of the article upon submission and before peer-review. There can be important differences between the submitted version and the official published version of record.

People interested in the research are advised to contact the author for the final version of the publication, or visit the DOI to the publisher's website.

- The final author version and the galley proof are versions of the publication after peer review.

- The final published version features the final layout of the paper including the volume, issue and page numbers.

Link to publication

\footnotetext{
General rights rights.

- You may freely distribute the URL identifying the publication in the public portal. please follow below link for the End User Agreement:

www.umlib.nl/taverne-license

Take down policy

If you believe that this document breaches copyright please contact us at:

repository@maastrichtuniversity.nl

providing details and we will investigate your claim.
}

Copyright and moral rights for the publications made accessible in the public portal are retained by the authors and/or other copyright owners and it is a condition of accessing publications that users recognise and abide by the legal requirements associated with these

- Users may download and print one copy of any publication from the public portal for the purpose of private study or research.

- You may not further distribute the material or use it for any profit-making activity or commercial gain

If the publication is distributed under the terms of Article $25 \mathrm{fa}$ of the Dutch Copyright Act, indicated by the "Taverne" license above, 
Short communication

\title{
External eating, impulsivity and attentional bias to food cues ${ }^{\text {is }}$
}

\author{
Ruihua Hou ${ }^{a}$, Karin Mogg ${ }^{b}, *$, Brendan P. Bradley ${ }^{b}$, Rona Moss-Morris ${ }^{b}$, Robert Peveler ${ }^{a}$, Anne Roefs $^{c}$ \\ ${ }^{a}$ Faculty of Medicine, University of Southampton, Southampton, United Kingdom \\ ${ }^{\mathrm{b}}$ School of Psychology, University of Southampton, Southampton, United Kingdom \\ ${ }^{\mathrm{c}}$ Department of Clinical Psychological Science, Maastricht University, Maastricht, The Netherlands
}

\section{A R T I C L E I N F O}

\section{Article history:}

Received 22 October 2010

Received in revised form 13 January 2011

Accepted 16 January 2011

Available online 21 January 2011

\section{Keywords:}

Food reward

Attentional bias

Impulsivity

External eating

Food cues

\begin{abstract}
A B S T R A C T
Cognitive and behavioural responses to food reward, such as attentional biases and overeating, have been associated with individual differences in reward-responsiveness and impulsivity. This study investigated relationships between external eating, impulsivity and attentional bias to food cues, assessed using the pictorial visual-probe task. As previously reported, attentional bias correlated positively with external eating. Additional novel findings were: (i) attentional bias for food cues was positively related to trait impulsivity, (ii) attentional bias remained related to attention impulsivity after controlling for external eating. Our findings highlight the relationship between the ability to control impulsive responding and selective attention to food cues.
\end{abstract}

(c) 2011 Elsevier Ltd. All rights reserved.

\section{Introduction}

According to recent research, a complex neural circuitry, including cortical and subcortical brain regions, controls cognitive and behavioural responses to food cues, and food intake (Beaver et al., 2006; Berridge, 2009; Davis et al., 2007; Rolls, 2010; Stice, Spoor, Ng, \& Zald, 2009; Stoeckel et al., 2008). The operation of this integrated network of brain regions provides a balance between involuntary stimulus-driven (bottom-up) processes and reflective goal-driven (top-down) processes, which together determine cognitive representations of the reward value of food cues, attentional responses to such cues, and impulsive behaviours (Rolls, 2010; Winstanley, Theobald, Cardinal, \& Robbins, 2004). Perturbation of these processes is likely to underlie a predisposition to overeat (Berridge, 2009; Rolls, 2010; Stice et al., 2009). The extent to which people show enhanced selective attention to food cues (i.e. attentional bias) provides an index of individual differences in reactivity to food reward, as determined by this integrated system. To gain insight into such individual differences, research has used objective methodology, such as the visual probe task, to assess attentional responses to food cues, which has the advantage of not relying on subjective self-report to assess attentional bias (Brignell, Griffiths, Bradley, \& Mogg, 2009; Hepworth, Mogg, Brignell, \& Bradley, 2010; Mogg, Bradley, Hyare, \& Lee, 1998; Pothos, Tapper, \& Calitri, 2009).

\footnotetext{
We thank Peter Dargie and Jin Zhang for experimental support.

* Corresponding author.

E-mail address: k.mogg@soton.ac.uk (K. Mogg).
}

One trait characteristic which has been identified as a vulnerability factor for overeating is 'external eating'. This refers to an increased tendency to eat in response to external cues, such as sight or smell of food. Findings from recent studies indicate that external eaters have an increased tendency to selectively attend to food cues (Brignell et al., 2009; Hepworth et al., 2010; Nijs, Franken, \& Muris, 2009). The first two studies used a wellestablished behavioural index of attentional bias derived from the pictorial version of the visual probe task, which presented pairs of pictures (e.g. food and non-food pictures), with each pair followed by a probe stimulus to which participants rapidly respond. Both studies showed that high-external eating is associated with faster detection of probes replacing food than non-food cues, indicating a greater attentional bias for pictorial food cues in external eaters.

In the context of the neurocognitive view outlined earlier, such findings may be explained by external eaters having increased sensitivity to food-reward cues and/or a poorer ability to regulate cognitive responses to food cues. This raises the question of the extent to which the attentional bias for food cues in external eaters may relate to a higher-order construct of trait impulsivity, reflecting a general predisposition for impulsive cognitive and behavioural responding to motivationally salient stimuli.

Impulsivity is widely acknowledged to be a complex multifaceted construct and, as noted by Stanford et al. (2009), one influential definition is as "a predisposition toward rapid, unplanned reactions to internal or external stimuli without regard to the negative consequences of these reactions to the impulsive individuals or to others" (Moeller, Barratt, Dougherty, Schmitz, \& Swann, 2001, p. 1784). Impulsivity has been assessed using a 
variety of methods including self-report and behavioural measures. One widely used self-report measure, the Barratt Impulsiveness Scale, identifies three components: inability to concentrate and focus attention (attention impulsiveness), acting without thinking (motor impulsiveness) and lack of future planning (non-planning impulsiveness) (Stanford et al., 2009). There has been some debate regarding the relationship between the constructs of impulsivity and sensitivity to reward, such as the extent to which the latter is an aspect of impulsivity or an independent construct (e.g. Franken \& Muris, 2006; Guerrieri, Nederkoorn, \& Jansen, 2007; Torrubia, Avila, Molto, \& Caseras, 2001).

Despite such theoretical controversies, trait impulsivity has been identified as a vulnerability factor for overeating (Guerrieri, Nederkoorn, \& Jansen, 2007; Guerrieri, Nederkoorn, Stankiewicz, et al., 2007) and a predictor of treatment outcome in obesity (Nederkoorn, Jansen, Mulkens, \& Jansen, 2007). Furthermore, research evidence from three recent studies show significant positive correlations between measures of impulsivity and external eating; e.g., $r=.51(p<.01)$ in 442 obese patients (mean BMI 40.5, SD = 5.3) (Elfhag \& Morey, 2008); $r=.23(p<.01)$ in 145 adult men (mean BMI 28.1, SD = 5.7) (Strimas et al., 2008), and $r=.17(p<.01)$ in 549 predominantly overweight or obese women (BMI 33.5, SD = 8.5) (Ouwens, van Strien, \& van Leeuwe, 2009).

Thus, external eating has been associated with both increased trait impulsivity and increased attentional bias to food cues. Consequently, the relationship between external eating and increased attentional bias to food cues may not be unique, but may be partly explained by the more general higher-order personality trait of impulsivity (i.e. impulsive individuals may be more likely to allocate attention to reward stimuli). However there is a lack of research evidence concerning the specific nature of these associations because previous studies showing a relationship between external eating and attentional bias for food cues did not assess trait impulsivity.

The overall aim of the present study was to investigate the relationships between external eating, impulsivity and attentional bias to food cues in a sample of healthy volunteers. Following previous research noted earlier, we hypothesized that external eating would be positively correlated with both attentional bias to food cues (Hypothesis 1) and trait impulsivity (Hypothesis 2). Furthermore, we predicted that increased attention to food cues would also be associated with greater impulsivity (Hypothesis 3 ) and that the relationship between attentional bias and impulsivity will remain even when controlling for external eating (Hypothesis 4).

\section{Methods}

\section{Participants}

Forty-four participants were recruited from students at the University of Southampton by advertising (e.g., posters and online). They completed an initial online screening using a short general information questionnaire, including items on demographic variables and eating habits, and the external eating scale of the Dutch Eating Behaviour Questionnaire (DEBQ) (Van Strien, Fritjers, Bergers, \& Defares, 1986). Recruitment favoured participants with omnivorous eating habits (vegetarians were excluded as they may respond atypically to pictures of meat), and those with high or low external eating scores (in order to minimise the proportion of the final sample with mid-range scores). Two participants were excluded due to outlying data (described later), so the final sample consisted of 29 women and 13 men, with a mean age of 22.0 years $(S D=4.7)$ years and mean BMI of 21.75 $(\mathrm{SD}=3.36)$. The study was carried out in accordance with approval from the School of Psychology Ethics Committee, University of Southampton.

\section{Visual probe task}

The visual probe task and stimuli, used to measure attentional bias, were similar to those previously used in our lab (Brignell et al., 2009; Hepworth et al., 2010), but used only one stimulus duration of $2000 \mathrm{~ms}$. The main stimuli comprised 20 food pictures (e.g. chocolate, cake, crisps, sandwich, fruit and pizza), each paired with a non-food picture matched as closely as possible for content (e.g., number, colour and shape of items). The non-food pictures depicted objects which are commonly found in the home but unrelated to food (e.g. book, pencils, toy, shampoo and sponge). Each picture pair was presented 4 times. An additional 10 pairs of non-food pictures were used as fillers, and an additional 10 pairs of food-control pictures for practice and buffer trials. Trial events consisted of a central fixation cross ( $500 \mathrm{~ms})$, replaced by a picture pair (2000 ms), followed by a probe (an asterisk) that appeared in the location of one of the preceding pictures (displayed until response). Participants were required to respond as quickly as possible by pressing one of two buttons to indicate the position of the probe. There were 10 practice trials and then 2 buffer trials immediately before the main block of 120 trials, which consisted of 80 trials with food-non-food picture pairs intermixed with 40 filler trials in random order. The picture pairs were displayed for $2000 \mathrm{~ms}$ only in the current study, as eye-movements were assessed while participants completed the task; however, technical problems prevented collection of sufficient eye-movement data for analyses.

\section{Questionnaire measures}

Following the attentional task, participants completed several questionnaires including:

(1) Dutch Eating Behaviour Questionnaire (DEBQ) (Van Strien et al., 1986) which is a 33-item questionnaire with three subscales: emotional eating, external eating and restrained eating.

(2) Barratt Impulsiveness Scale (BIS) (Spinella, 2007). This 15-item version assesses trait impulsivity, and retains the 3-factor structure of the full version of the BIS (Patton, Stanford, \& Barratt, 1995), which are attention impulsivity (inattention and cognitive instability), motor impulsivity (motor impulsiveness and lack of perseverance), and non-planning (lack of selfcontrol and intolerance of cognitive complexity).

(3) Behavioural activation system (BAS) scale (Carver \& White, 1994), which includes three subscales of fun-seeking, reward responsiveness and drive.

(4) Sensitivity to reward (SR) scale of the Sensitivity to Punishment and Sensitivity to Reward (SPSR) Questionnaire (Torrubia et al., 2001).

(5) Grand Hunger Scale (Grand, 1968), which includes ratings of subjective hunger and desire to eat right now (see Brignell et al., 2009, for details). This measure was included as state hunger may influence attention to food cues (Mogg et al., 1998).

(6) A supplementary questionnaire assessed demographic and background information. Also, height and weight were measured to calculate BMI (weight $[\mathrm{kg}] /$ height $^{2}\left[\mathrm{~m}^{2}\right]$ ).

\section{Preparation of data}

Reaction time (RT) data from trials with incorrect responses were excluded. RTs less than $200 \mathrm{~ms}$, more than $1500 \mathrm{~ms}$, and then more than 2 SD above each participant's mean were excluded as 
outliers. Attentional bias scores were calculated for each participant by subtracting the mean RT for probes replacing food pictures from the mean RT for probes replacing control pictures. An attentional bias for food cues is indicated by a positive bias score, whereas an attentional bias away from food cues is indicated by a negative bias score.

Two participants were excluded from the analyses due to outlying data: one had an unusually high BIS impulsivity score (55) which was more than 3 SD above the mean of Spinella's (2007) norms $(M=32.6 ; \mathrm{SD}=6.9, N=700)$; another had an outlying attentional bias score $(-86 \mathrm{~ms})$, which was more than 3 SD below the sample mean $(M=4 \mathrm{~ms} ; \mathrm{SD}=27, N=44)$. KolmogorovSmirnov tests indicated that, for the remaining 42 participants, the distribution of each score was within normal limits, except BAS reward, which was consequently reflected (i.e. each score was subtracted from a constant that was one greater than the highest score) and log-transformed to remove positive skewness before analyses.

\section{Results}

Pearson correlations were used to assess the relationships between attentional bias $(M=6 \mathrm{~ms}, \mathrm{SD}=24, N=42)$, external eating $(M=3.4, \mathrm{SD}=0.5)$ and impulsivity (overall BIS: $M=32.7$, $\mathrm{SD}=6.8$; attention-impulsivity: $M=10.6, \mathrm{SD}=2.6$; motor-impulsivity: $M=11.1, \mathrm{SD}=3.0$; non-planning-impulsivity: $M=10.9$, $\mathrm{SD}=2.9$ ).

External eating correlated significantly with increased attentional bias for food cues $(r=.36, p<.05$; i.e. support for Hypothesis 1 ). External eating also correlated positively with trait impulsivity measured by the overall BIS score $(r=.56, p<.05$; i.e. support for Hypothesis 2) and particularly with attention and motor impulsivity subscales of the BIS ( $r$ s were .63 and .45 , respectively, $p s<.05)$. External eating also positively correlated with reward sensitivity (SR subscale of SPSR, $r=.42, p<.05$ ) and the funseeking subscale of the BAS $(r=.51, p<.05)$.

Attentional bias for food cues significantly correlated not only with external eating (as noted above), but also with the overall index of trait impulsivity $(r=.42, p<.05$; i.e. support for Hypothesis 3), including both attention and motor impulsivity BIS subscales ( $r$ s were .48 and .40 , respectively, $p s<.05$ ). Attentional bias was also associated with greater BAS fun-seeking $(r=.32, p<.05)$. There were no other significant zero-order correlations of interest; for example, reward sensitivity (SR) did not correlate significantly with attentional bias $(r=.22, n s)$, although it was positively associated with external eating and impulsivity ( $r$ s were .42 and .33 , respectively, $p s<.05$ ). In addition, BAS reward, BAS drive, emotional eating, restrained eating and self-reported hunger were not significantly correlated with BIS impulsivity or attentional bias (e.g. bias correlated .03 with BAS reward and -.07 with BAS drive, both $n s$ ).

Partial correlations were conducted to clarify the significant relationships between the attentional bias, external eating and impulsivity measures. Results showed that the attentional bias to food cues remained significantly correlated with BIS attention impulsivity after controlling the effects of DEBQ external eating $(r=.36, p=.02)$, and BAS fun-seeking $(r=.42, p=.01)$. The attentional bias showed near-significant trends to correlate positively with BIS motor impulsivity after removing effects of DEBQ external eating $(r=.29, p=.07)$, and BAS fun-seeking $(r=.28, p=.08)$.

In contrast, the attentional bias to food cues was no longer significantly correlated with external eating after controlling the effects of BIS impulsivity (partial correlations between attentional bias and external eating were $r=.08, p=.64$, when controlling attention impulsivity; $r=.22, p=.18$, controlling motor impulsivity; and $r=.16, p=.31$, controlling overall BIS); i.e. support for
Hypothesis 4. The attentional bias to food cues was also not significantly correlated with BAS fun-seeking $(r=.12, p=.46)$ after controlling for BIS impulsivity.

\section{Discussion}

The current study is the first, to our knowledge, to show a significant positive correlation between attentional bias for food cues and trait impulsivity. Attentional bias also significantly correlated with external eating, which was expected from prior research. Partial correlation analyses indicated that the relationship between attentional bias and attention impulsivity remained significant even after controlling the effect of external eating.

The present finding of the positive correlation between external eating and attentional bias to pictorial food cues confirmed our first hypothesis and is consistent with results from two previous studies from our lab using a similar task (Brignell et al., 2009; Hepworth et al., 2010). In the latter two studies, the correlation coefficients between external eating and attentional bias were .42 and .39 , respectively, which indicated a large effect size and are comparable with the correlation of .36 found in the present study. Thus, the association between self-reported predisposition to eat in response to external food cues and a bias in selective attention to food appears to be a robust feature of healthy adults, as indicated by these non-clinical studies using the pictorial version of the visual probe task. One recent study using the visual probe task failed to find a significant relationship between external eating and attentional bias (Pothos et al., 2009); however, this study used single words as cues rather than food-related pictures. Images of food have greater ecological validity than words and, consequently, may be more potent in eliciting attentional biases.

The significant positive correlation between the self-report measures of external eating and impulsivity in this study confirmed our second hypothesis and is also consistent with previous research findings noted earlier (Elfhag \& Morey, 2008; Ouwens et al., 2009; Strimas et al., 2008). These previous studies found this association in samples who were predominantly obese or overweight (mean BMI in the latter studies ranged from 28 to 40). The present results further indicate that external eating and impulsivity are linked in an average healthy-weight sample (mean BMI of $22, S D=3$ ). Reward sensitivity was also positively correlated with both external eating and impulsivity. Thus, in the present sample, the trait measure of external eating shared a considerable amount of variance with higher-order constructs of trait impulsivity (31\% shared variance) and reward sensitivity (18\% shared variance), which is consistent with common underlying mechanisms mediating responses to rewards.

This study also extended previous research by investigating the extent to which the enhanced attentional bias for food cues in external eaters was related to trait impulsivity. The significant positive correlation between attentional bias and impulsivity confirmed our third hypothesis and suggests that impulsive individuals are more likely to allocate attention to food-reward stimuli than non-impulsive individuals. Results from partial correlation analyses further indicated that the attentional bias for food cues was significantly associated with attention impulsivity, when controlling for external eating. In addition, there was no association between attentional bias and external eating after taking account of trait individual differences in attention impulsivity (partial correlation was close to zero). Thus, the present results are novel in indicating that attention impulsivity has a key relationship with attentional bias.

We also examined relationships with specific components of impulsivity, which have been identified in previous research (Patton et al., 1995; Spinella, 2007). The two components of attention and motor impulsivity both significantly correlated with 
external eating, which is consistent with significant relationships between these two elements of impulsivity and disinhibited eating reported by Lyke and Spinella (2004). Attention and motor impulsivity were also both significantly related to attentional bias. The lack of association between the non-planning element of impulsivity and either external eating or attentional bias measures in this study suggested that non-planning impulsivity is a functionally distinct measure from motor and attention impulsivity (Fischer, Smith, \& Anderson, 2003), and not specifically related to individual differences in cognitive-behavioural responses to food. The differential relationships between BIS impulsivity subscales and other measures are also consistent with the view that impulsivity is not a unitary phenomenon as indicated in previous research (Patton et al., 1995; Spinella, 2007).

The current study has implications for understanding individual differences in cognitive-behavioural responses to external food cues. The present findings may be understood within a neurocognitive framework (outlined earlier) in which integrated brain mechanisms determine individual differences in reward sensitivity and cognitive control (Davis, 2009). These systems underlie not only the ability to control cognitive and behavioural responding to motivational salient stimuli more generally (as indexed by the selfreport measure of impulsivity measure used here), but also, more specifically, cognitive-behavioural responses to food, as indexed by the measure of attentional bias used in the present study.

Several limitations of the study may be noted. First, the study design was cross-sectional in nature, which prevents causal interpretations of the relationships between impulsivity and attentional bias to food cues. Second, the data were from a selected student sample, the majority of whom were women. Third, the main focus here was on one measure of attentional bias, which was obtained from the visual probe task. It should be noted that attentional bias is not a unitary construct (Mogg \& Bradley, 1998) and it would be helpful to see whether the present findings generalise across other measures of attentional bias, such as the modified Stroop task, which has been found to predict weight gain in non-obese individuals (Calitri, Pothos, Tapper, Brunstrom, \& Rogers, 2010).

In conclusion, the present study revealed a significant positive relationship between individual differences in trait attention impulsivity and selective attention to food cues in an average healthy-weight sample. Thus, future research is warranted to clarify the role of trait impulsivity in determining cognitive and behavioural responses to food cues not only in non-clinical normal-weight samples, but also in samples with more problematic eating habits. Such research may reveal that training in attention manipulation and impulse control may be potential intervention targets for individuals with obesity.

\section{References}

Beaver, J. D., Lawrence, A. D., van Ditzhuijzen, J., Davis, M. H., Woods, A., \& Calder, A. J. (2006). Individual differences in reward drive predict neural responses to images of food. Journal of Neuroscience, 26, 5160-5166.

Berridge, K. C. (2009). 'Liking' and 'wanting' food rewards. Brain substrates and roles in eating disorders. Physiology and Behavior, 97, 537-550.

Brignell, C., Griffiths, T., Bradley, B. P., \& Mogg, K. (2009). Attentional and approach biases for pictorial food cues. Influence of external eating. Appetite, 52, 299-306.

Calitri, R., Pothos, E. M., Tapper, K., Brunstrom, J. M., \& Rogers, P. J. (2010). Cognitive biases to healthy and unhealthy food words predict change in BMI. Obesity doi:10.1038/oby.2010.78 Epub 8 April 2010.
Carver, C. S., \& White, T. L. (1994). Behavioral inhibition, behavioral activation, and affective responses to impending reward and punishment. The BIS/BAS scales. Journal of Personality and Social Psychology, 67, 319-333.

Davis, C. (2009). Psychobiological traits in the risk profile for overeating and weight gain. International Journal of Obesity, 33(Suppl. 2), S49-S53.

Davis, C., Patte, K., Levitan, R., Reid, C., Tweed, S., \& Curtis, C. (2007). From motivation to behaviour. A model of reward sensitivity, overeating, and food preferences in the risk profile for obesity. Appetite, 48, 12-19.

Elfhag, K., \& Morey, L. C. (2008). Personality traits and eating behavior in the obese. Poor self-control in emotional and external eating but personality assets in restrained eating. Eating Behaviors, 9, 285-293.

Fischer, S., Smith, G. T., \& Anderson, K. G. (2003). Clarifying the role of impulsivity in bulimia nervosa. International Journal of Eating Disorders, 33, 406-411.

Franken, I. H. A., \& Muris, P. (2006). Gray's impulsivity dimension: A distinction between Reward Sensitivity versus Rash Impulsiveness. Personality and Individual Differences, 40, 1337-1347.

Grand, S. (1968). Color-word interference. II. An investigation of the role of vocal conflict and hunger in associative priming. Journal of Experimental Psychology, 77, $31-40$.

Guerrieri, R., Nederkoorn, C., \& Jansen, A. (2007). How impulsiveness and variety influence food intake in a sample of healthy women. Appetite, 48, 119-122.

Guerrieri, R., Nederkoorn, C., Stankiewicz, K., Alberts, H., Geschwind, N., Martijn, C., et al. (2007). The influence of trait and induced state impulsivity on food intake in normal-weight healthy women. Appetite, 49, 66-73.

Hepworth, R., Mogg, K., Brignell, C., \& Bradley, B. P. (2010). Negative mood increases selective attention to food cues and subjective appetite. Appetite, 54, 134142

Lyke, J. A., \& Spinella, M. (2004). Associations among aspects of impulsivity and eating factors in a nonclinical sample. International Journal of Eating Disorders, 36, 229233.

Moeller, F. G., Barratt, E. S., Dougherty, D. M., Schmitz, J. M., \& Swann, A. C. (2001). Psychiatric aspects of impulsivity. American Journal of Psychiatry, 158, 17831793.

Mogg, K., \& Bradley, B. P. (1998). A cognitive-motivational analysis of anxiety. Behaviour Research and Therapy, 36, 809-848.

Mogg, K., Bradley, B. P., Hyare, H., \& Lee, S. (1998). Selective attention to food-related stimuli in hunger. Are attentional biases specific to emotional and psychopathological states, or are they also found in normal drive states? Behaviour Research and Therapy, 36, 227-237.

Nederkoorn, C., Jansen, E., Mulkens, S., \& Jansen, A. (2007). Impulsivity predicts treatment outcome in obese children. Behaviour Research and Therapy, 45, 1071-1075.

Nijs, I. M. T., Franken, I. H. A., \& Muris, P. (2009). Enhanced processing of food-related pictures in female external eaters. Appetite, 53, 376-383.

Ouwens, M. A., van Strien, T., \& van Leeuwe, J. F. (2009). Possible pathways between depression, emotional and external eating. A structural equation model. Appetite, 53, 245-248.

Patton, J. H., Stanford, M. S., \& Barratt, E. S. (1995). Factor structure of the Barratt impulsiveness scale. Journal of Clinical Psychology, 51, 768-774.

Pothos, E. M., Tapper, K., \& Calitri, R. (2009). Cognitive and behavioral correlates of BMI among male and female undergraduate students. Appetite, 52, 797-800.

Rolls, E. T. (2010). Taste, olfactory, and food texture reward processing in the brain and obesity. International Journal of Obesity doi:10.1038/ijo.2010.155 Epub 3 August 2010.

Spinella, M. (2007). Normative data and a short form of the Barratt Impulsiveness Scale. The International Journal of Neuroscience, 117, 359-368.

Stanford, M. S., Mathias, C. W., Dougherty, D. M., Lake, S. L., Anderson, N. E., \& Patton, J. H. (2009). Fifty years of the Barratt Impulsiveness Scale. An update and review. Personality and Individual Differences, 47, 385-395.

Stice, E., Spoor, S., Ng, J., \& Zald, D. H. (2009). Relation of obesity to consummatory and anticipatory food reward. Physiology \&' Behavior, 97, 551-560.

Stoeckel, L. E., Weller, R. E., Cook, E. W., III, Twieg, D. B., Knowlton, R. C., \& Cox, J. E. (2008). Widespread reward-system activation in obese women in response to pictures of high-calorie foods. Neuroimage, 41, 636-647.

Strimas, R., Davis, C., Patte, K., Curtis, C., Reid, C., \& McCool, C. (2008). Symptoms of attention-deficit/hyperactivity disorder, overeating, and body mass index in men. Eating Behaviors, 9, 516-518.

Torrubia, R., Avila, C., Molto, J., \& Caseras, X. (2001). The Sensitivity to Punishment and Sensitivity to Reward Questionnaire (SPSRQ) as a measure of Gray's anxiety and impulsivity dimensions. Personality and Individual Differences, 31, 837-862.

Van Strien, T., Fritjers, J. E. R., Bergers, G. P. A., \& Defares, P. B. (1986). Dutch Eating Behaviour Questionnaire for assessment of restrained, emotional and external eating behaviour. International Journal of Eating Disorders, 5, 295-315.

Winstanley, C. A., Theobald, D. E., Cardinal, R. N., \& Robbins, T. W. (2004). Contrasting roles of basolateral amygdala and orbitofrontal cortex in impulsive choice. Journal of Neuroscience, 24, 4718-4722. 